\title{
“Tá lá o corpo estendido no chão...”: a Violência Letal contra Travestis no Município do Rio de Janeiro
}

\author{
SÉRGIO CARRARA * \\ ADRIANA R. B. VIANNA •
}

\section{RESUMO}

Partindo de uma pesquisa mais ampla acerca da violência letal que atinge gays e travestis e a forma como tais casos são construídos judicialmente, este artigo busca destacar alguns elementos relevantes para a compreensão das dinâmicas sociais em jogo quando as vítimas são travestis. O perfil social das vítimas, as características distintivas dos próprios crimes e, sobretudo, as peculiaridades relativas a seu tratamento pela polícia e nas instâncias do Judiciário apontam para a importância de investigar os matizes e nuanças da violência homofóbica. Como fica claro no universo de processos judiciais trabalhados, as relações entre cor, classe e gênero desempenham papel fundamental no modo como tal violência é exercida, socialmente codificada e, por fim, punida.

Palavras-chave: Travestis; Justiça; violência; homofobia.

Recebido em: 13/11/2006.

Aprovado em: 04/12/2006. 


\section{Introdução}

Nas grandes metrópoles brasileiras, sujeitos cuja identidade nãoheterossexual (suposta ou certa) é mais evidente através da exibição ou incorporação de atributos de gênero não-conformes ao sexo designado no nascimento são proporcionalmente mais atingidos por diferentes modalidades de violência e discriminação. A desestabilização provocada por sua performance de gênero, constantemente associada a um conjunto de estereótipos negativos sobre a homossexualidade em geral, torna as travestis as vítimas preferenciais de violência homofóbica em diferentes contextos. ${ }^{1}$ Nesse sentido, o grau de exposição a atos violentos separa muito nitidamente diferentes categorias gays, lésbicas e travestis - freqüentemente agrupadas sob a genérica rubrica de "homossexuais". O presente artigo busca não apenas contribuir para que se conheçam os contextos de interação social em que homossexuais acabam vitimados, mas sobretudo analisar o modo como os aparatos policiais e judiciais reagem a esse tipo de violência quando a vítima é travesti. ${ }^{2}$

Os dados aqui discutidos foram produzidos no âmbito de uma investigação mais ampla conduzida entre janeiro de 2000 e julho de 2001, com o objetivo de conhecer como os tribunais brasileiros vêm respondendo à chamada "violência contra homossexuais", especificamente nos casos que resultam em morte. ${ }^{3}$ Nossa questão inicial dizia respeito ao modo pelo qual a homossexualidade influía no andamento das investigações e como os casos eram apreciados por policiais, juizes, promotores, defensores etc. Ou seja, queríamos aferir o modo pelo qual a homofobia se fazia presente no sistema de justiça e se o fato de a vítima ser homossexual implicava a impunidade dos acusados. Interessava-nos particularmente perceber se valores tradicionalmente ligados à honra masculina apareciam como justificativa para esse tipo de crime e se argumentos amparados por esses valores eram aceitos pelos operadores do direito.

O ponto de partida do estudo foram os dados presentes em dossiê produzido pelos ativistas do Grupo 28 de Junho, composto por uma compilação de recortes de jornal pertinentes à violência contra homossexuais. ${ }^{4}$ Embora não se tratasse de levantamento sistemático de referências na imprensa, o dossiê permitiu identificar 200 casos noticiados como assassinatos de "homossexuais" no município do Rio de Janeiro, entre as décadas de 70 e 90. Através da Assessoria de Planejamento da Polícia Civil (ASPLAN), foi possível levantar informações relativas a 105 homicídios, envolvendo 108 vítimas, todas do sexo masculino, classificadas como "homossexuais" pelos jornais. ${ }^{5}$ 
Como primeira notificação oficial de um crime, o Registro de Ocorrência (RO) fornece informações mais precisas do que os jornais sobre a vítima, as testemunhas, o crime e o eventual suspeito. Em 57 crimes tais informações foram complementadas com as presentes nas peças do inquérito policial e do processo penal, localizados em diferentes varas criminais cariocas. ${ }^{6}$ Ao longo da análise dos inquéritos policiais e processos, percebemos ser possível agrupar os casos em três categorias mais ou menos discretas, utilizando como critérios principais de classificação a relação entre assassinos e vítimas e a motivação do crime. A primeira delas diz, grosso modo, respeito aos crimes enquadrados no artigo 157 do Código Penal, relativo ao latrocínio, ou seja, a casos de roubo seguido de morte. Seguindo a classificação proposta por Ramos e Borges (2000), denominamos tais casos "crimes de lucro". Os crimes em que havia indícios de que vítima e assassino se conheciam e nos quais não ficou comprovada qualquer intenção de roubo foram classificados por nós como "crimes interativos" e envolviam diferentes tipos de conflito, alguns dos quais no âmbito de relações amorosas. Por fim, a terceira categoria agregava os casos de execução por arma de fogo, tendo, sobretudo, travestis como vítimas.

De modo geral, os dados revelaram que o tipo de violência letal que incide sobre travestis, bem como o perfil sociológico desse tipo de vítima, é bem diferente da que tende a atingir outros homens não-heterossexuais. Tomando como base a classificação de cor atribuída por policiais e médicos legistas, pode-se sugerir que entre as travestis vitimadas há predominância de negros e pardos, indicativo de seu pertencimento aos estratos mais pobres da sociedade brasileira, enquanto entre os gays, ou seja, homossexuais que não exibem tão claramente as marcas de sua "diferença", predominam indivíduos classificados como brancos, com alta escolaridade e oriundos das camadas médias urbanas.

Diferentemente das travestis, os gays tendem a ser vitimados em casa, por meio de arma branca, asfixia ou objeto contundente (60,7\% dos casos), compondo a esmagadora maioria das vítimas letais dos crimes de lucro. Os assassinatos de travestis, por sua vez, têm lugar mais freqüientemente na rua, por arma de fogo (68\% dos casos), correspondendo quase todos a crimes de execução. Os casos de execução são maciçamente arquivados (78\%). Para outras formas de violência letal contra homossexuais, a taxa de arquivamentos mantém-se alta, mas cai para 50\%, enquanto a de condenações eleva-se sensivelmente (CARRARA \& VIANNA 2004a). Esses dados sinalizam para o grau da impunidade que incide sobre a execução de travestis, sendo importante 
investigar o modo pelo qual tal impunidade se constrói. É isto que procuraremos discutir nas partes que se seguem.

\section{Execuções, travestis e o descaso policial}

Foram classificados como casos de execução os assassinatos em que não havia indicativos de que vítima e acusado mantivessem relações regulares ou em que a motivação para o crime não estivesse ligada à consecução de lucro imediato através do roubo de algum pertence. Nesses casos havia o predomínio absoluto de armas de fogo como instrumento letal (12 dos 14 assassinatos foram cometidos com armas de fogo), ocorrendo o crime predominantemente na rua (apenas um dos casos, uma dupla execução, envolvendo homens encapuzados, foi realizada dentro de casa). Os casos de execução têm como vítimas sobretudo travestis ou homossexuais que apresentavam indicativos externos de cross-dressing, como unhas pintadas, pêlos do corpo raspados ou roupas femininas (10 dos 14 casos analisados). Em dois outros casos, as vítimas são definidas por policiais ou depoentes como "homossexuais", e em mais dois, embora as vítimas sejam classificadas pela imprensa como "homossexuais", isso não aparece de forma clara no inquérito. Em marcado contraste com os crimes de latrocínio ou de lucro, outro dado que chama a atenção é a idade relativamente precoce das vítimas, inferior a 35 anos. No que diz respeito à sua cor, negros e pardos respondem por cerca de $40 \%$ dos casos.

As execuções respondem pelo mais baixo número de acusados identificados. Dos 14 processos reunidos, em apenas dois há o indiciamento de acusados, sendo um deles absolvido e apenas um condenado. Faz parte das justificativas para o arquivamento de tais casos a dificuldade em reunir informações sobre o crime ou mesmo sobre a vítima, em razão dos assassinatos ocorrerem em locais definidos pelos policiais como ermos ou favelas (nove casos). Dos casos ocorridos em ruas movimentadas, por sua vez, apenas um teve lugar fora da Zona Sul do Rio de Janeiro, acontecendo em Realengo, enquanto os demais se deram em Laranjeiras (um), em Ipanema (um) e em Copacabana (dois).

Mesmo nos episódios em que emergem testemunhas ou informantes, costuma haver grande resistência em prestar maiores informações sobre a vítima ou o crime. Em dois casos, o silêncio de vizinhos e familiares parece 
estar relacionado ao fato de o crime ter sido motivado por algum envolvimento das vítimas com o tráfico de drogas, como fica claro no triplo homicídio que vitimou, com mais duas pessoas, o "homossexual" VIS. ${ }^{7}$ No relatório pertinente a esse crime, o delegado responsável reporta que "as mortes podem ter ocorrido como 'queima de arquivo' [...] e possivelmente os familiares com medo de envolvimento forneceram endereços inexistentes" (Proc. 1.559/87), impossibilitando sua localização. Já no duplo homicídio que vitimou o homossexual JABM e um amigo, a própria mãe da vítima declarou que ouviu tiros após seu filho ter sido retirado por homens encapuzados e armados de sua casa na Favela da Biquinha, em Jacarepaguá, mas que teve medo de verificar o que ocorria. A polícia declara ter tido que encerrar o caso por falta de indícios e informantes.

Nos assassinatos de travestis, o procedimento usual registrado nos inquéritos é o de apurar informações sobre a vítima em zonas morais que seriam frequientadas por outras travestis, redundando em resultados negativos. A se tomar como verdadeira a afirmação dos policiais, esse dado poderia indicar, por um lado, a resistência de travestis em fornecer informações à polícia e, por outro, sua marginalização mais intensa quando comparadas a outros homossexuais. Tal marginalização é evidenciada pelo fato de que três das 14 vítimas de execução permaneceram não-identificadas até a conclusão do inquérito. De modo geral, portanto, a baixa resolução dos casos de execução parece ser condicionada por um conjunto de fatores, entre os quais gênero e classe social, que se combinam para colocar as travestis entre os grupos socialmente mais desfavorecidos.

Esse quadro de investigações precárias se agrava ainda mais quando há evidência de participação de travestis em atividades de prostituição ou de tráfico de drogas - como nos casos da morte da travesti Bárbara, em 27/09/90, cujo corpo foi encontrado em um capinzal próximo aos arcos da Lapa, no Centro do Rio de Janeiro, ou na de ACS, cognominada Débora, ocorrido em 05/07/90. ${ }^{8}$ No caso de Bárbara, o policial que encontra o corpo diz ter apurado com populares que se tratava de "travesti dali mesmo" (Proc. 3.643/90) e que era comum que travestis envolvidas com prostituição levassem clientes para aquele local, sugerindo que a autoria do crime seria de um parceiro sexual. Não foram, porém, levantadas mais informações sobre a vítima ou o assassinato, o que denota certa naturalidade na forma de encarar sua execução.

Já no caso do assassinato de Débora - ocorrido na Rua do Senado, também no Centro do Rio de Janeiro - a hipótese de envolvimento da vítima 
com o tráfico de drogas foi levantada pelo detetive responsável em seu relatório, no qual sugere que "grupos de traficantes estariam recrutando travestis para serviço de distribuição de tóxicos" (Proc. 3.461/90). Embora nesse caso a família identifique o corpo, não parece ter havido grande empenho na cobrança pela resolução do crime. A mãe da vítima, por exemplo, declarou que já sabia qual seria o destino do filho, que "freqüentava a Lapa e o Estácio" e era "portador do vírus da Aids" (idem).

O descaso policial em tais situações nem sempre é aceito pacificamente pelo Judiciário, como também ocorre em alguns casos de latrocínio. ${ }^{9}$ Em dois processos, houve menção explícita ao pouco empenho dos policiais em levantar informações sobre o assassinato. No caso do assassinato de JS, ocorrido em 05/ 09/86 na Rua Oswaldo Seabra, em Laranjeiras, o Ministério Público contrariou o relatório do delegado responsável pelo caso. Enquanto este afirmava que as possibilidades de diligência haviam se esgotado, o promotor argumentou que muitas alternativas ainda não haviam sido exploradas e que era "só uma questão de querer" (Proc. 927/86). De forma ainda mais contundente, o promotor responsável pelo caso de assassinato da travesti conhecida por "Índia", morta a tiros em frente ao estádio do Maracanã na madrugada do dia 09/09/84, escreve que "este é mais um inquérito em que fica patenteado o desinteresse da Polícia Civil em apurar crimes, que é sua função principal. Mais de oito anos se passaram e nada foi feito de prático!" (Proc. 4.625/84). A indignação do promotor parece estar ligada ao fato de que sequer procedimentos mínimos, como a tomada de depoimento de pessoas que identificaram a travesti como "Índia", indicando inclusive seu local de moradia, foram levados adiante pela polícia.

Em outros casos, mesmo que no processo não conste nenhuma crítica explícita ao procedimento policial, fica claro que os esforços no sentido de identificar testemunhas ou apurar melhor as causas do crime foram muito precários. Exemplo desse tipo de investigação deficitária emerge no processo de WSA, cujo corpo foi encontrado com vários tiros na Avenida Automóvel Clube, em 08/08/90. Os primeiros depoimentos, prestados por familiares da vítima, só foram recolhidos oito anos após a abertura do inquérito, não fornecendo nenhum elemento que pudesse ajudar a elucidar o caso. Procedimento semelhante ocorreu na apuração do assassinato de WLS encontrada alvejada por três tiros, numa casa abandonada em Anchieta, Zona Norte do Rio de Janeiro, em 05/11/90. Embora constem do Registro de Ocorrência informações dadas por um homem de nome Pascoal, que estava com a vítima, e um terceiro homem bebendo em uma barraca antes do 
assassinato, o depoimento deste informante não foi tomado. A única declaração formal que consta do inquérito, por sinal, prestada pelo irmão da vítima, está datada de 06/03/92, ou seja, um ano e quatro meses após o crime ter ocorrido.

\section{A ordem da lei e a desordem das travestis}

Em contraste com o conjunto dos casos acima delineado, destacam-se os dois únicos casos de execução em que um suspeito é apontado, indiciado e levado a julgamento. O primeiro deles diz respeito ao assassinato da travesti CEPC, conhecida como Kátia, pelo policial militar JAOD, em 23/02/91. O assassinato ocorreu em Copacabana, no local onde a vítima exercia a prostituição, e recebeu versões bastante diferentes de acordo com as diversas testemunhas chamadas a depor. Segundo a versão do acusado, a vítima estaria participando de assalto associada a outras duas travestis. Ante a intervenção do policial, Kátia, descontrolada, teria segurado a arma de JAOD, fazendo-a disparar sem intenção. Ainda segundo essa versão, as travestis estariam armadas com canivetes e JAOD teria contado com a ajuda de um amigo na tentativa de controlar a vítima, o segurança de lojas PRR (que, em depoimento posterior, ao Tribunal do Júri, declara tê-lo conhecido apenas na ocasião). Este, por sua vez, oferece uma versão um pouco diferente do caso. Segundo as declarações de PRR, o que o motivou a intervir foi uma briga em que Kátia e outra travesti atacavam um terceiro. Este último, ao ser ameaçado, recebeu o apoio do acusado, que acabou por disparar sua arma contra Kátia.

Nas declarações do acusado e de PRR, indiciado sem ter sido levado a julgamento, aparecem representações que também estão presentes nos depoimentos de parte das testemunhas. Segundo PRR, no local seria "muito comum a freqüência de aglomeração de travestis [...], que é muito comum estes elementos praticarem toda sorte de perturbações naquele local" (Proc. 3.828/91). O acusado, por sua vez, declara que não prestou socorro à vítima por ter sido cercado por "muitos travestis, mais ou menos vinte”, reforçando a idéia de "aglomeração" e de uma ação coordenada, o que é relevante em outros depoimentos.

As testemunhas, por sua vez, parecem dividir-se em dois grupos principais: aquelas que enfatizam a idéia de que um conflito entre travestis teria sido o estopim do crime e as que acreditam ter sido esse conflito forjado pelas próprias travestis para encobrir um assalto em curso. Esse embate de versões, 
mais do que discutir o fato em si, apresenta representações importantes sobre a vítima, sobre o acusado e sobre travestis em geral. É significativo que essa divisão obedeça também a uma diferença crucial entre as personagens que testemunham - travestis que se prostituem no próprio local em oposição aos moradores da área.

Segundo uma das travestis presentes à cena do crime, conhecida por $\mathrm{Lu}$, dois homens (o acusado e PRR) batiam na vítima quando ela se aproximou, pedindo que ambos parassem com a agressão. Em reação à sua interferência, o acusado teria apontado uma arma para Lu e para outra travesti, sendo em seguida atacado por Kátia, o que ocasionou o disparo da arma. Cerca de seis meses após prestar esse depoimento na delegacia, Lu envia uma carta à $1^{\mathrm{a}}$ Vara Criminal, onde o caso estava tramitando, declarando que

gostaria de esclarecer o assassinato de Kátia [...] porém não posso fazer, tendo em vista as pressões sofridas, por PM e Paulo [PRR] que ameaçaram de morte (sic), motivo pelo qual tive de me afastar de Copacabana, devo dizer que o motivo do crime é que tanto o PM quanto Paulo [PRR] exploravam os travestis, quem não desse a sua devida cota não mais poderia freqüentar aquele local. O PM é sangüinário, ameaçador, e Paulo não fica atrás, não posso aparecer aí senão vai acontecer o que aconteceu com Kátia” (idem).

Embora Lu seja a única das travestis a depor que indica diretamente a possibilidade de uma ligação prévia entre os envolvidos, outras travestis contradizem senão integralmente a versão dos acusados, ao menos a versão de que um assalto teria sido o elemento detonador do conflito. De acordo com as travestis Fernando e Emílio, o conflito teria sido iniciado a partir de uma briga entre as travestis, sendo que Fernando e a vítima estavam envolvidos. Segundo Emílio, por sua vez, a intervenção do acusado teria sido feita com o objetivo de defender Fernando, atacado pela vítima.

A versão do assalto, desmentida pelas travestis, é confirmada por uma testemunha, que teria sido vítima da tentativa de assalto em questão. Nos depoimentos de moradores da área e policiais - mesmo daqueles que não testemunharam diretamente o assalto - essa possibilidade se apresenta como a mais aceitável, funcionando como elemento importante para definição de uma imagem geral das travestis. Assim, um dos policiais militares chamados a depor declara que "é comum os travestis praticarem assaltos na área" e que, quando chegava como policial para apurar um desses assaltos, as travestis 
"simulavam briga para confundir a polícia". Declara ainda, visando obviamente a desvalorizar os depoimentos prestados por travestis na delegacia, que "os travestis se unem em defesa um do outro, até testemunhando em favor dos mesmos" e "que os moradores do local já fizeram um abaixoassinado pedindo providência à polícia contra os travestis" (idem). As mesmas idéias são defendidas por outro policial, que enfatiza "que é comum os travestis defenderem-se mutuamente, até testemunhando contra a verdadeira vítima em defesa de outro travesti". As imagens das travestis provocando "tumultos" ou "confusões" e simulando brigas para encobrir assaltos é reforçada ainda por dois moradores do local, desenhando o que se suporia um comportamento padrão e coletivo de travestis.

O conflito de versões parece ter sido importante para que o juiz da $1^{\mathrm{a}}$ Vara Criminal não aceitasse a definição do caso como homicídio culposo, tomando-o como doloso e, com isso, levando o réu ao Tribunal do Júri. Tal posição é criticada pela defesa, que apela dessa decisão declarando que

o prolator [...] apreciou, tão somente, o depoimento de JES, homossexual que atende pelo apodo de Lu, que sequer foi ouvido pelo MM Juiz a quo, desprezando, absolutamente, os esclarecimentos prestados por testemunhas idôneas e oculares.

Ao chamar atenção para a idoneidade das testemunhas, a defesa coloca em posição desfavorável, em termos de credibilidade e imagem social, não apenas a testemunha que está sendo criticada - Lu - mas também a vítima. Ambas são desacreditadas por meio de estereótipos acerca de uma forma de agir "característica" de travestis, que incluiria tumulto, assaltos e uma perigosa solidariedade de grupo que, como visto, as conduziria a prestar informações falseadas como forma de proteção mútua. Neste processo em especial, essa contraposição acaba por favorecer o acusado, que é absolvido. Em outro caso, porém, embora representações muito semelhantes estejam em jogo, o resultado final desenha-se diferente, como veremos em seguida.

Em 01/11/86 a travesti ALS, conhecida por Paula, foi morta em Ipanema pelo motorista de um carro que passava no local. Duas outras travestis testemunharam o crime, declarando que momentos antes Paula tinha corrido em sua direção contando que o motorista de uma Belina havia lhe apontado uma arma e, em reação, ela havia atirado uma pedra no carro e fugido com medo. Enquanto uma das travestis procurava um táxi para a vítima, esta correu 
para a outra esquina, acabando por encontrar-se com o mesmo carro, que havia dado a volta no quarteirão e sendo atingida por um tiro.

Outra travesti, conhecida por Gabriela, cerca de um ano após o crime declara em depoimento na delegacia ter sabido da morte de Paula em um bar em Copacabana no dia seguinte ao ocorrido, tendo tido conhecimento também de que o autor do crime era um homem conhecido por Edu, que era companheiro de outra travesti, conhecida por Roberta. Pouco tempo depois, a polícia identifica o suspeito Edu como sendo ASJ. Curiosamente, o acusado não é procurado por este crime, mas por outro que havia cometido (uma tentativa de homicídio realizada com outra pessoa) e pelo qual havia sido detido em flagrante. Levado à delegacia, ASJ inicialmente declara conhecer várias travestis, diversas com o nome Roberta e não se lembrar de onde estava na ocasião, em razão do tempo decorrido. Declara também fazer trabalhos de "X9" para a polícia e que seu carro na época era uma Caravan preta, e não uma Belina prata como a que havia sido vista por testemunhas. $\mathrm{O}$ detetive responsável pelo caso, segundo seu próprio relatório, adota então a estratégia de convencê-lo de que já dispunham de várias testemunhas e que, caso continuasse a negar a autoria do crime, perderia a possibilidade de se beneficiar com atenuantes. ASJ acaba por confessar o crime, oferecendo sua primeira versão para o ocorrido.

De acordo com a primeira versão, ele passava com o carro de seu tio por Ipanema quando decidiu parar para oferecer carona a uma travesti, esquecendo o farol alto ligado. Outras travestis que estavam no local protestaram, inclusive Paula, que o teria ofendido e atirado uma pedra no vidro de seu carro. Declara que deu a volta no quarteirão para alcançar Paula, que havia fugido e se escondido atrás de um carro e, quando este voltou a xingá-lo, teria lhe dito "olha, você vai morrer agora", atirando em seguida. Essa versão sofre duas mudanças na medida em que o processo corre na justiça. Em 08/08/88 declara que, ao deixar "descuidadamente" os faróis altos ligados foi atacado por quatro ou mais pessoas que corriam em sua direção arremessando pedras, sendo que uma delas atingiu seu carro. Apavorado, segundo suas palavras, havia disparado a arma em direção às pessoas que corriam, acabando por atingir Paula. Cerca de um ano depois, já no depoimento que presta em seu julgamento, o acusado altera mais uma vez a versão, dizendo que estava em Ipanema dando carona a um colega de trabalho quando "viu uma pessoa de cor escura e forte tentando abrir o pino da porta do carona do seu carro, que [...] ficou apavorado e não conseguiu fazer o carro pegar" (Proc. 1.011/86) acabando por atirar em direção à porta do carro, onde estava Paula. 
Mais significativas que as mudanças de versão sobre o ocorrido, porém, parece ser o embate entre as imagens a respeito do acusado e da principal testemunha a incriminá-lo, a travesti ZGA, conhecida por Roberta, que depõe na fase judicial. Segundo suas declarações, o acusado era seu companheiro na ocasião do crime, tendo dito ao chegar em casa que havia matado uma travesti por essa ter atirado uma pedra em seu carro. Roberta declara ainda ter sido ameaçada pelo acusado na delegacia quando ambos estavam lá detidos, tendo ASJ lhe dito na ocasião "já matei uma morena e agora vou matar uma loura" (idem). Informa ainda que ASJ teria por companheira no momento em que presta depoimento uma outra travesti, conhecida por Shirley.

$\mathrm{O}$ acusado nega ter qualquer relacionamento com Roberta, o que é enfaticamente reforçado pela defesa. Procurando caracterizá-lo como um filho dedicado, "arrimo de família tradicional", a defesa busca, por um lado, definir o crime como legítima defesa e, por outro, desqualificar a principal testemunha. A razão para o acusado ter-se sentido amedrontado, diz a defesa, foi estar sozinho,

à noite, em local onde assaltos e badernas se sucedem a ponto de moradores insistirem em pedir proteção policial. Ponto de encontro de travestis e de homossexuais que atacam pedestres, veículos, famílias. E o único "crime" praticado pelo acusado, no momento, foi o de ter esquecido os faróis altos de seu carro, quando parou para atender ao sinal vermelho do trânsito. As piranhas então atacaram [...] Quem, à noite, em local desprotegido, como in caso e na época presente, vendo seu veículo rodeado por diversas pessoas que gritavam e atiravam pedradas não procuraria se defender da melhor maneira possível" (idem, grifo nosso).

As mesmas representações sobre travestis presentes no caso anterior aparecem no trecho acima: a noção de ação conjunta (a defesa invoca a imagem de várias travestis atacando o acusado, e não apenas uma) e de uma variedade de "tumultos" que seriam provocados pela simples presença de travestis em determinado local. Note-se aqui que aparece também na argumentação da defesa a contraposição entre travestis e homossexuais, por um lado, e pedestres, veículos e famílias por outro, com os últimos perdendo sua tranqüilidade de moradores em razão de estarem "desprotegidos". A contraposição - e a homofobia nela presente - fica ainda mais evidente nas tentativas de desqualificação da principal testemunha, a travesti Roberta. Nas palavras da defesa: 
o travesti falado nem sequer provou a sua verdadeira identidade, sendo certo que, ao tomar suas declarações o próprio e digno Dr. Juiz, até mesmo em tom irônico disse: "Não sei se o chamo de Z ou se pelo nome de mulher que usa" [...] e, neste caso, também a defesa exigiu que tal personagem trouxesse para os autos a prova de sua exata identificação. Afinal de contas, quem é? Afinal de contas, perante a justiça há de se ter dignidade e personalidade (idem).

Percebe-se nas palavras da defesa que a ambigüidade do nome sugere uma ambigüidade maior e, por isso, mais perigosa ou capaz de causar desordem simbólica. A idéia de que a "verdadeira identidade" está oculta ou confusa, impedindo a "dignidade e personalidade" exigidas pela situação casa-se com as representações mais gerais de desordem que estariam presentes nas situações envolvendo travestis. Frente a tais ambigüidades, a ação criminosa poderia ser percebida apenas como reação, como tentativa de colocar em ordem ou defender direitos legítimos que seriam prejudicados pela atuação sempre coletiva de travestis.

Não parece haver, até aqui, grandes diferenças entre o caso anterior, que resulta na absolvição do acusado e este, que resulta na sua condenação. A se crer nos termos da defesa, mesmo o Juiz partilha do incômodo com relação à "dupla identidade" da testemunha principal, incômodo esse que pode facilmente se estender à vítima. A diferença, como policiais deixam claro em seus relatórios, parece estar nos procedimentos do acusado e, em especial, na sua ligação com travestis. Para que a contraposição pretendida pela defesa fosse eficaz, seria necessário que a imagem que se tenta construir do acusado, como trabalhador, bom filho etc., pudesse se impor sem contradições. Isso, entretanto, não acontece.

O detetive encarregado do caso aponta em seu relatório que a versão de "legítima defesa" não era verdadeira, e que "ASJ é um homem 'chegado a travestis' e seu relacionamento com eles é constante e bem chegado" (idem). O delegado responsável, por sua vez, traça um quadro igualmente negativo do acusado, dizendo ter esse uma "vida ligada à pederastia e à prostituição, bem como alcagüete (sic), condutas tão repugnantes como a própria motivação do crime" (idem, grifo nosso). Ou seja, o ponto decisivo na condenação do acusado está no fato deste não conseguir construir uma imagem distante dos mesmos elementos utilizados para desqualificar a principal testemunha. Nesse sentido, a informação de que o acusado teria, na época do julgamento, outra travesti por companheira reforça essa representação negativa, eliminando a tentativa, bem-sucedida no caso anterior, de alinhar acusados do 
lado da ordem (defesa frente à tentativa de assalto, reação instintiva de defesa da vida e do patrimônio) e vítimas do lado da desordem (prostituição, ambigüidade de gênero, "tumultos").

\section{Considerações finais}

Como procuramos sinalizar neste artigo, as travestis parecem ser particularmente vulneráveis aos crimes de execução. Isso se deve tanto ao envolvimento com a atividade de prostituição, que as coloca numa posição de maior exposição pública, quanto ao modo pelo qual a homofobia as atinge. Assim, há casos em que a identidade de gênero suposta da vítima, o fato de "ser travesti", parece ser o fator determinante da execução - que assume as feições de um crime de ódio. Em outros casos a motivação parece estar associada a outras circunstâncias, como seu envolvimento com o tráfico de drogas ou em conflitos relativos a problemas quanto ao pagamento de "taxas de proteção" a cafetões ou cafetinas que controlam determinados pontos de prostituição de travestis.

Revelando-se principalmente nas execuções de travestis, temos a evocação de uma imagem da desordem urbana, em que o duplo desvio sexual (homossexualidade e prostituição) aparece conectado à pobreza, ao tráfico e às favelas. Bandos que atacam carros, assaltam moradores, provocam arruaças. Embora sob protestos de alguns agentes da lei, travestis acabam sendo assassinadas sem que muito se faça para esclarecer o caso. Como vimos, no caso em que uma execução desse tipo foi punida, o réu acabou sendo, dadas as relações que mantinha com travestis, engolfado pela imagem da desordem, tornando-se moralmente indistinguível de sua vítima.

Por envolverem no conjunto da nossa amostra majoritariamente travestis, os casos de execução chamam a atenção para a presença de diferentes hierarquias sociais no universo homossexual e, com isso, para a diversidade e complexidade das práticas homofóbicas. Nesses casos, há uma clara confluência entre hierarquia de classe e gênero, já que as vítimas são normalmente travestis ou homossexuais pobres, envolvidos com prostituição ou moradores de favelas, que carregam o peso mais estigmatizante da homossexualidade.

A indiferença policial na apuração da maior parte desses crimes parece encontrar eco nas representações negativas de travestis como homossexuais especialmente desajustados, de modo que sua morte, em geral em idade bem inferior do que a das vítimas de latrocínio, tende a ser tomada 
por policiais como conseqüência de um modo de vida constantemente próximo da ilegalidade e que é recebida com poucas pressões, sobretudo familiares, por sua apuração e por justiça.

\section{Referências}

BENEDETTI, M. R. Toda feita: corpo e gênero das travestis. Rio de Janeiro: Garamond, 2005.

CARRARA, S.; VIANNA, A. R. B. A violência letal contra homossexuais no município do Rio de Janeiro: características gerais. In: CÁCERES, C. F. et al. (Orgs.). Ciudadanía sexual en América Latina: abriendo el debate. Lima: Universidad Peruana Cayetano Heredia, 2004(a).

As vítimas do desejo: os tribunais cariocas e a homossexualidade nos anos 1980. In: PISCITELLI, A.; GREGORI, M. F.; CARRARA, S. (Orgs.). Sexualidade e saberes: convenções e fronteiras. Rio de Janeiro: Garamond, 2004(b).

CARRARA, S.; RAMOS, S.; CAETANO, M. Política, direitos, violência e homossexualidade (Pesquisa $8^{\text {a }}$ Parada do Orgulho GLBT - Rio). Rio de Janeiro: Pallas, 2003.

CARRARA, S.; RAMOS, S. Política, direitos, violência e homossexualidade (Pesquisa $9^{\text {a }}$ Parada do Orgulho GLBT - Rio). Rio de Janeiro: CLAM/IMSUERJ, 2004.

KULIC, D. Travesti: Sex, Gender and Culture among Brazilian Transgender Prostitutes. Chicago: University of Chicago Press, 1998.

MOTT, L. Violação dos direitos humanos e assassinato de homossexuais no Brasil. Salvador: Grupo Gay da Bahia, 2000.

MOTT, L.; CERQUEIRA, M. Causa mortis: homofobia. Salvador: Grupo Gay da Bahia, 2001.

RAMOS, S.; BORGES, D. Disque Defesa Homossexual: números da violência. Comunicações do ISER, v. 20, n. 56, p. 67-78, 2000.

SILVA, H. Travesti, a invenção do feminino. Rio de Janeiro: Relume Dumará, 1993. 
"Tá lá o corpo estendido no chão..."

\section{NOTAS}

- Antropólogo, professor adjunto no Instituto de Medicina Social e coordenador do CentroLatino Americano em Sexualidade e Direitos Humanos (CLAM-IMS/UERJ). Endereço eletrônico: carrara@ims.uerj.br.

- Antropóloga, professora adjunta no Museu Nacional (UFRJ). Endereço eletrônico: adrianavianna@gmail.com.

${ }^{1}$ Pesquisa sobre vitimização de homossexuais são ainda raras no país. A partir de 2003, o Centro Latino-Americano em Sexualidade e Direitos Humanos (CLAM-IMS/UERJ) e o Centro de Estudos de Segurança e Cidadania (UCAM), em parceira com diferentes centros de pesquisa e grupos ativistas, vêm procurando reverter esse quadro. Em parceria com o Grupo Arco-Íris, aquelas instituições aplicaram questionários sobre vitimização junto aos manifestantes das paradas de orgulho de gays, lésbicas, bissexuais e transgêneros no Rio de Janeiro em 2003 e 2004. Em 2003, enquanto 16,6\% de todos os entrevistados reportaram já terem sido vítimas de agressão física devido à sua orientação sexual ou sexualidade, essa porcentagem sobe para 42,3\%, quando se trata de transgêneros (travestis e transexuais). Em 2004, enquanto a incidência geral desse tipo de agressão era de 18,7\%, entre o(a)s transgêneros, ela subia para 33,3\% (ver CARRARA; RAMOS e CAETANO, 2003; CARRARA e RAMOS, 2004).

${ }^{2}$ A categoria "travesti”, neste caso, diz respeito não à auto-identificação de um sujeito em termos de sua identidade sociossexual, mas a sua performance de gênero e modelação do corpo: assinalamos através dela aqueles casos em que a vítima exibia indicativos de cross-dressing e/ou alterações anatômicas, segundo relatos de agentes de justiça, polícia ou testemunhas. A categoria “gay”, por sua vez, é empregada por referência ao conjunto dos casos em que a vítima referida como homossexual não apresentava esses mesmos indícios. Ao considerar esse conjunto heterogêneo como "homossexuais" não estamos nos baseando nas práticas propriamente eróticas dos indivíduos, ou mesmo no modo como se definem. Não é raro que travestis recusem a categoria "homossexual", enfatizando que, ao se relacionarem com homens, estão mantendo, em verdade relações heterossexuais. Desse modo, a "homossexualidade" aqui indicada circunscreve um complexo de performances de gênero enquadradas enquanto tal por aqueles que são nossos atores-chave: policiais, operadores do direito, bem como os produtores e consumidores das notícias acerca dos assassinatos.

${ }^{3}$ Com o apoio da Fundação Ford do Brasil, a pesquisa contou em suas diferentes etapas com a participação de Marcelo Natividade, Sabrina Paiva e Leandro Oliveira. 
${ }^{4}$ Trabalho mais sistemático sobre violência letal contra homossexuais a partir da imprensa tem sido feito pelo Grupo Gay da Bahia - ver Mott (2000) e Mott \& Cerqueira (2001).

${ }^{5}$ A não-localização de muitos casos deveu-se principalmente ao fato de não serem precisas as informações que a imprensa oferece sobre o local do crime, a data de ocorrência ou os nomes de vítima e acusados. Além disso, como nossos dados revelaram, nem sempre a homossexualidade da vítima que aparece nos jornais se confirma na documentação presente nos arquivos policiais. Para um panorama dos dados obtidos nessa pesquisa, ver Carrara \& Vianna (2004a).

${ }^{6}$ De fato, em $28 \%$ dos casos, não encontramos qualquer referência à homossexualidade nos registros de ocorrência ou nos processos. Resolvemos, entretanto, não excluir qualquer uma das vítimas em nossa análise, uma vez que, ou mantinham práticas homossexuais, embora tal fato não figurasse na documentação consultada, ou a modalidade de violência que os atingiu parecia ao senso comum de policiais e jornalistas ser do mesmo tipo da que costumaria atingir homossexuais.

${ }^{7}$ Embora homicídios sejam crimes de ação pública que dão origem a processos que podem ser consultados sem autorização de vítimas ou acusados, resolvemos evitar a citação dos nomes constantes dos processos, utilizando apenas iniciais ou pseudônimos.

${ }^{8}$ Para a dinâmica das atividades de prostituição entre travesti ver, entre outros, Silva (1993), Benedetti (2005) e Kulic (1998).

${ }^{9}$ Para uma análise mais detida dos latrocínios perpetrados contra homossexuais, ver Carrara \& Vianna (2004b). 
"Tá lá o corpo estendido no chão..."

\section{ABSTRACT}

\section{Lethal Violence Against Travestis in Rio de Janeiro City}

Based on a broad research on lethal violence which affects gays and travestis, and the way such cases are judicially built, this paper aims to highlight some important elements to help understand the social dynamics played when travestis are the victims. The victims' social profile, the distinctive characteristics of the crimes and, most of all, the peculiarities of the police's and the Judiciary's behavior point to the need for investigating colorings and nuances of homophobic violence. The analyzed judicial processes clearly show that color, class and gender relations play an important role in the way such violence occurs, is socially codified and, finally, is punished.

Key words: Travestis; Justice; violence; homofobia. 